\title{
Impact of Right Ventricular Dilatation in Patients with Atrial Septal Defect
}

\author{
Rie Nakayama, ${ }^{1}$ Yoichi Takaya $\mathbb{D}^{1},{ }^{1}$ Teiji Akagi, ${ }^{1}$ Koji Nakagawa, ${ }^{1}$ Nobuhisa Watanabe, ${ }^{2}$ \\ Saori Nobusada, ${ }^{2}$ Toshi Matsushita, ${ }^{2}$ Norihisa Toh, ${ }^{1}$ Susumu Kanazawa, ${ }^{3}$ and Hiroshi Ito ${ }^{1}$ \\ ${ }^{1}$ Department of Cardiovascular Medicine, Okayama University Graduate School of Medicine, \\ Dentistry and Pharmaceutical Sciences, Okayama, Japan \\ ${ }^{2}$ Division of Medical Support, Okayama University Hospital, Okayama, Japan \\ ${ }^{3}$ Department of Radiology, Okayama University Graduate School of Medicine, Dentistry and Pharmaceutical Sciences, \\ Okayama, Japan \\ Correspondence should be addressed to Yoichi Takaya; takayayoichi@okayama-u.ac.jp
}

Received 15 January 2020; Accepted 25 February 2020; Published 28 April 2020

Academic Editor: Martin J. Swaans

Copyright (C) 2020 Rie Nakayama et al. This is an open access article distributed under the Creative Commons Attribution License, which permits unrestricted use, distribution, and reproduction in any medium, provided the original work is properly cited.

\begin{abstract}
Objective. The aim of this study was to examine the relationship between right ventricular (RV) volume and exercise capacity in adult patients with atrial septal defect (ASD) and to determine the degree of RV dilatation for transcatheter ASD closure. Background. RV dilatation is an indication of transcatheter ASD closure; however, few studies have reported the clinical significance of RV dilatation. Methods. We enrolled 82 consecutive patients (mean age, $49 \pm 18$ years; female, $68 \%$ ) who underwent cardiac magnetic resonance imaging and symptom-limited cardiopulmonary exercise test before ASD closure. The relationship between $\mathrm{RV}$ volume and peak oxygen uptake $\left(\mathrm{VO}_{2}\right)$ was evaluated. Results. The mean $\mathrm{RV}$ end-diastolic volume index was $108 \pm 27 \mathrm{ml} / \mathrm{m}^{2}$ (range, 46 to $180 \mathrm{ml} / \mathrm{m}^{2}$ ). The mean peak $\mathrm{VO}_{2}$ was $24 \pm 7 \mathrm{ml} / \mathrm{min} / \mathrm{kg}$ (range, 14 to $48 \mathrm{ml} / \mathrm{min} / \mathrm{kg}$ ), and the mean predicted peak $\mathrm{VO}_{2}$ was $90 \pm 23 \%$. There were significant negative relationships of $\mathrm{RV}$ end-diastolic volume index with peak $\mathrm{VO}_{2}$ $(r=-0.28, p<0.01)$ and predicted peak $\mathrm{VO}_{2}(r=-0.29, p<0.01)$. The cutoff value of $\mathrm{RV}$ end-diastolic volume index $<80 \%$ of predicted peak $\mathrm{VO}_{2}$ was $120 \mathrm{ml} / \mathrm{m}^{2}$, with the sensitivity of $49 \%$ and the specificity of $89 \%$. Conclusions. There was a relationship between RV dilatation and exercise capacity in adult patients with ASD. RV end-diastolic volume index $\geq 120 \mathrm{ml} / \mathrm{m}^{2}$ was related to the reduction in peak $\mathrm{VO}_{2}$. This criterion of $\mathrm{RV}$ dilatation may be valuable for the indication of transcatheter ASD closure.
\end{abstract}

\section{Introduction}

Atrial septal defect (ASD) is the most common congenital heart disease with a left-to-right shunt in adults and is recognized in $7 \%$ of all congenital heart diseases [1]. Many patients with ASD are asymptomatic in adulthood, but a reduction in exercise capacity and exertional shortness of breath appear at over 40 years old [2-5]. Currently, transcatheter closure is a general therapy for secundum ASD $[6,7]$. A significant left-to-right shunt causing right ventricular (RV) dilatation is an accepted indication of ASD closure [8]. Several studies have reported that transcatheter ASD closure results in RV remodeling and exercise capacity improvement [9-13]. However, the relationship between RV dilatation and the reduction in exercise capacity before ASD closure remains unclear. Furthermore, there is no criterion of RV dilatation for performing ASD closure. Cardiac magnetic resonance (CMR) imaging can accurately quantify RV volume. Thus, we hypothesized that RV dilatation evaluated by CMR imaging was closely related to exercise capacity. The aim of this study was to examine the relationship between RV volume and exercise capacity in patients with ASD and to determine the degree of RV dilatation for ASD closure.

\section{Methods}

2.1. Study Population. We enrolled 82 consecutive adult patients with secundum ASD who underwent CMR imaging 
and symptom-limited cardiopulmonary exercise test (CPET) from January 2016 to August 2019 at Okayama University Hospital. Patient population in this study was $36 \%$ of all patients who underwent ASD closure. Indications for ASD closure were a significant left-to-right shunt, RV volume overload, and/or clinical symptoms of heart failure or paradoxical embolism. Patients with severe pulmonary arterial hypertension who received specific medications were excluded. After right heart catheterization was performed for hemodynamic evaluation such as pulmonary to systemic flow ratio (Qp/Qs), mean pulmonary artery pressure, cardiac output, and cardiac index, transcatheter ASD closure was performed in all patients without any complications using an Amplatzer septal occluder device (Abbott, Chicago, IL, USA) or an Occlutech Figulla Flex II device (Occlutech GmbH, Jena, Germany).

All patients gave written informed consent for the examinations. The study was approved by the ethical committee of our institution.

2.2. Cardiac Magnetic Resonance Imaging. CMR imaging studies were performed on a 1.5-T scanner (Siemens AG, Erlangen, Germany) under electrocardiogram synchronization before ASD closure. The endocardial and epicardial contours of both ventricles were manually traced on the short axis end-diastolic and end-systolic phases using software (Ziostation; Ziosoft, Tokyo, Japan). RV end-diastolic volume, RV end-systolic volume, RV ejection fraction, left ventricular (LV) end-diastolic volume, and LV endsystolic volume were evaluated.

2.3. Echocardiography. Transthoracic echocardiography was performed in all patients before ASD closure. RV end-diastolic basal diameter, RV end-diastolic area, and RV endsystolic area were evaluated in the apical 4-chamber view. To assess RV function, tricuspid annular plane systolic excursion (TAPSE), tricuspid annular systolic velocity (S), and RV fractional area change (FAC) were measured. LV end-diastolic diameter, LV end-systolic diameter, and LV ejection fraction were also measured. ASD diameter was measured by transesophageal echocardiography.

2.4. Cardiopulmonary Exercise Test. A maximum symptomlimited CPET was performed using a bicycle ergometer before ASD closure. The workload was increased by 15 watts/min. Patients exercised until exhaustion. Oxygen uptake $\left(\mathrm{VO}_{2}\right)$, carbon dioxide production $\left(\mathrm{VCO}_{2}\right)$, and minute ventilation (VE) were assessed by breath-by-breath gas analysis. Peak $\mathrm{VO}_{2}$, predicted peak $\mathrm{VO}_{2}$, peak work, ventilatory equivalent for carbon dioxide ( $\mathrm{VE} / \mathrm{VCO}_{2}$ slope), and respiratory exchange ratio were evaluated. Peak $\mathrm{VO}_{2}$ was defined as the highest value recorded during the last minute of exercise. Predicted peak $\mathrm{VO}_{2}$ was determined by age and sex.

2.5. Statistical Analysis. Data are presented as mean\pm standard deviation for continuous variables and as number and percentage for categorical variables. Pearson's correlation coefficient was used to assess relationships between CMR imaging and echocardiographic parameters with exercise capacity. Linear regression analysis was performed for multivariate analysis. The cutoff value of RV volume for the reduction in exercise capacity was estimated using receiver operating characteristic curve. Statistical analysis was performed with JMP version 14.0 (SAS Institute Inc., Cary, NC, USA), and significance was defined as a value of $p<0.05$.

\section{Results}

3.1. Patient Characteristics. The study population consisted of 82 patients (female: $68 \%$ ) with mean age of $49 \pm 18$ years. Patient characteristics are shown in Table 1 . The majority of patients had New York Heart Association functional class I. ASD diameter was $15 \pm 6 \mathrm{~mm}$. The Qp/Qs was $2.2 \pm 0.8$, and the mean pulmonary artery pressure was $16 \pm 5 \mathrm{mmHg}$.

3.2. Cardiac Magnetic Resonance Imaging and Echocardiography. CMR imaging and echocardiographic parameters are summarized in Table 2. CMR imaging showed RV end-diastolic volume index of $108 \pm 27 \mathrm{ml} / \mathrm{m}^{2}$ (range, 46 to $180 \mathrm{ml} / \mathrm{m}^{2}$ ) and $\mathrm{RV}$ end-systolic volume index of $78 \pm 19 \mathrm{ml} / \mathrm{m}^{2}$ (range, 34 to $122 \mathrm{ml} / \mathrm{m}^{2}$ ). Echocardiography showed RV end-diastolic basal diameter of $46 \pm 6 \mathrm{~mm}$, $\mathrm{RV}$ end-diastolic area of $27 \pm 6 \mathrm{~cm}^{2}$, and RV end-systolic area of $15 \pm 3 \mathrm{~cm}^{2}$. As the parameters of RV function, TAPSE was $25 \pm 4 \mathrm{~mm}$, S was $15 \pm 2 \mathrm{~cm} / \mathrm{s}$, and RV FAC was $45 \pm 4 \%$.

3.3. Cardiopulmonary Exercise Test. CPET parameters are summarized in Table 2. Peak $\mathrm{VO}_{2}$ was $24 \pm 7 \mathrm{ml} / \mathrm{min} / \mathrm{kg}$ (range, 14 to $48 \mathrm{ml} / \mathrm{min} / \mathrm{kg}$ ), and predicted peak $\mathrm{VO}_{2}$ was $90 \pm 23 \%$. Fifty-one patients (62\%) had predicted peak $\mathrm{VO}_{2} \geq 80 \%$, 30 patients (37\%) had predicted peak $\mathrm{VO}_{2}$ $60-80 \%$, and one patient $(1 \%)$ had predicted peak $\mathrm{VO}_{2}$ $<60 \%$.

3.4. Relationships of Cardiac Magnetic Resonance Imaging and Echocardiography with Cardiopulmonary Exercise Test. Regarding CMR imaging, the enlargement of RV end-diastolic volume index was related to the reduction in peak $\mathrm{VO}_{2}$ $(r=-0.29, p<0.01)$ and predicted peak $\mathrm{VO}_{2}(r=-0.24$, $p=0.03$ ) (Figure 1). RV ejection fraction was negatively related to peak $\mathrm{VO}_{2}(r=-0.30, p<0.01)$. There were no relationships of LV end-diastolic volume index or LV endsystolic volume index with exercise capacity (Table 3). Multivariate linear regression analysis showed that RV enddiastolic volume index was independently related to the reduction in peak $\mathrm{VO}_{2}$ (Table 4).

Regarding echocardiography, RV end-diastolic basal diameter and RV end-diastolic area were related to the reduction in peak $\mathrm{VO}_{2}(r=-0.30, p<0.01 ; r=-0.25$, $p=0.03$, respectively). TAPSE, $\mathrm{S}$, or RV FAC was not related to exercise capacity. 
TABle 1: Patient characteristics.

\begin{tabular}{lc}
\hline Variables & \\
\hline Age (yrs) & $49 \pm 18$ \\
Female & $56(68 \%)$ \\
Body surface area $\left(\mathrm{m}^{2}\right)$ & $1.6 \pm 0.2$ \\
New York Heart Association functional class I & $63(\%)$ \\
New York Heart Association functional class II & $35(\%)$ \\
New York Heart Association functional class III & $1(\%)$ \\
Atrial fibrillation & $5(6 \%)$ \\
Diuretics & $11(13 \%)$ \\
ASD diameter $(\mathrm{mm})$ & $15 \pm 6$ \\
Qp/Qs & $2.2 \pm 0.8$ \\
Mean pulmonary artery pressure $(\mathrm{mmHg})$ & $16 \pm 5$ \\
Cardiac output, $(\mathrm{L} / \mathrm{min})$ & $4.3 \pm 1.3$ \\
Cardiac index, $\left(\mathrm{L} / \mathrm{min} / \mathrm{m}^{2}\right)$ & $2.7 \pm 0.8$ \\
\hline
\end{tabular}

Data are presented as mean \pm standard deviation or number (\%) of patients. $\mathrm{ASD}=$ atrial septal defect; Qp/Qs = pulmonary to systemic flow ratio.

TABLE 2: CMR imaging, echocardiography, and CPET parameters.

\begin{tabular}{lc}
\hline Variables & \\
\hline CMR imaging & \\
RV end-diastolic volume index $\left(\mathrm{ml} / \mathrm{m}^{2}\right)$ & $108 \pm 27$ \\
RV end-systolic volume index $\left(\mathrm{ml} / \mathrm{m}^{2}\right)$ & $78 \pm 19$ \\
RV ejection fraction $(\%)$ & $27 \pm 7$ \\
LV end-diastolic volume index $\left(\mathrm{ml} / \mathrm{m}^{2}\right)$ & $54 \pm 12$ \\
LV end-systolic volume index $\left(\mathrm{ml} / \mathrm{m}^{2}\right)$ & $30 \pm 9$ \\
Echocardiography & \\
RV end-diastolic basal diameter $(\mathrm{mm})$ & $46 \pm 6$ \\
RV end-diastolic area $\left(\mathrm{cm}^{2}\right)$ & $27 \pm 6$ \\
RV end-systolic area $\left(\mathrm{cm}^{2}\right)$ & $15 \pm 3$ \\
RV FAC (\%) & $45 \pm 4$ \\
TAPSE (mm) & $25 \pm 4$ \\
S (cm/s) & $15 \pm 2$ \\
LV end-diastolic diameter (mm) & $41 \pm 4$ \\
LV end-systolic diameter (mm) & $26 \pm 4$ \\
LV ejection fraction $(\%)$ & $66 \pm 9$ \\
CPTE & \\
Peak oxygen uptake (ml/kg/min) & $24 \pm 7$ \\
Predicted peak oxygen uptake $(\%)$ & $90 \pm 23$ \\
Peak work (watts) & $104 \pm 36$ \\
Ventilatory equivalent for carbon dioxide slope & $23 \pm 3$ \\
Respiratory exchange ratio & $1.2 \pm 0.1$ \\
\hline Da
\end{tabular}

Data are presented as mean \pm standard deviation. $\mathrm{CMR}=$ cardiac magnetic resonance; $\mathrm{CPET}=$ cardiopulmonary exercise test; $\mathrm{FAC}=$ fractional area change; $L V=$ left ventricular; $R V=$ right ventricular; $S=$ tricuspid annular systolic velocity; TAPSE $=$ tricuspid annular plane systolic excursion .

3.5. Degree of Right Ventricular Dilatation. The optimal cutoff value of RV end-diastolic volume index $<80 \%$ of predicted peak $\mathrm{VO}_{2}$ was $120 \mathrm{ml} / \mathrm{m}^{2}$ (area under the curve $=0.69$ ), with the sensitivity of $49 \%$ and the specificity of $89 \%$.

\section{Discussion}

The major findings of the present study were as follows: (1) there was a significant negative relationship between RV end-diastolic volume and exercise capacity in patients with ASD; (2) RV end-diastolic volume was the independent
TABLE 3: Relationships of CMR imaging and echocardiography with exercise capacity.

\begin{tabular}{lcccc}
\hline & \multicolumn{3}{c}{ Peak $\mathrm{VO}_{2}$} & \multicolumn{2}{c}{$\begin{array}{c}\text { Predicted peak } \\
\text { Variables }\end{array}$} & & & $\mathrm{VO}_{2}$ \\
& $r$ & $p$ value & $r$ & $p$ value \\
\hline CMR imaging & & & & \\
RV end-diastolic volume index & -0.29 & $<0.01$ & -0.24 & 0.03 \\
RV end-systolic volume index & 0.05 & 0.15 & 0.13 & 0.23 \\
RV ejection fraction & -0.30 & $<0.01$ & -0.24 & 0.03 \\
LV end-diastolic volume index & 0.04 & 0.09 & 0.03 & 0.78 \\
LV end-systolic volume index & 0.11 & 0.34 & 0.03 & 0.78 \\
Echocardiography & & & & \\
RV basal diameter & -0.30 & $<0.01$ & -0.09 & 0.43 \\
RV end-diastolic area & -0.25 & 0.03 & -0.09 & 0.41 \\
RV end-systolic area & -0.24 & 0.03 & -0.08 & 0.47 \\
RV FAC & 0.05 & 0.69 & 0.02 & 0.83 \\
TAPSE & 0.05 & 0.66 & 0.09 & 0.83 \\
S & 0.14 & 0.21 & $<0.01$ & 0.94 \\
LV end-diastolic diameter & 0.22 & 0.04 & 0.02 & 0.85 \\
LV end-systolic diameter & 0.22 & 0.04 & $<0.01$ & 0.97 \\
LV ejection fraction & 0.08 & 0.45 & 0.04 & 0.27 \\
\hline
\end{tabular}

$\mathrm{CMR}=$ cardiac magnetic resonance; $\mathrm{FAC}=$ fractional area change; $\mathrm{LV}=$ left ventricular; $\mathrm{RV}=$ right ventricular; $\mathrm{S}=$ tricuspid annular systolic velocity; TAPSE $=$ tricuspid annular plane systolic excursion; $\mathrm{VO}_{2}=$ oxygen uptake

factor related to reduced peak $\mathrm{VO}_{2}$; and (3) the cutoff value of $\mathrm{RV}$ end-diastolic volume index for reduced peak $\mathrm{VO}_{2}$ was $120 \mathrm{ml} / \mathrm{m}^{2}$. To the best of our knowledge, this study is the first study to show the relationship between RV dilatation and the reduction in exercise capacity before ASD closure and to indicate the criterion of $\mathrm{RV}$ dilatation for reduced peak $\mathrm{VO}_{2}$.

Most patients with ASD have impaired exercise capacity with age $[14,15]$. RV volume overload because of a left-toright shunt causes enlargement of the right ventricle, leading to clinical symptoms such as dyspnea and fatigue. Exercise capacity depends on the left-to-right shunt and RV volume overload. RV dilatation may represent a limiting factor. However, the relationship between RV dilatation and peak $\mathrm{VO}_{2}$ before ASD closure has not been fully investigated.

Reduced exercise capacity is associated with decreased LV stroke volume and cardiac output in patients with ASD [12]. Altered interventricular interaction induced by longstanding RV volume overload plays a central role in limiting exercise tolerance [14]. Because of RV dilatation, the interventricular septum bulges paradoxically and encroaches into LV cavity, impairing LV filling and thus both diastolic and systolic performance [16-18]. This mechanism could cause decreased cardiac output, leading to reduced peak $\mathrm{VO}_{2}$. After transcatheter ASD closure, the abolishment of the left-to-right shunt leads to augmented LV filling by preload and therefore to increased cardiac output [14]. Many studies have reported that transcatheter ASD closure results in a positive RV remodeling and improved exercise capacity [9-13]. The improvement in cardiac form following increased cardiac output is the most likely factor leading to improved peak $\mathrm{VO}_{2}$ [19]. In this study, cardiac output was not markedly decreased. It might be compensated by RV hypercontraction with the dilatation. However, RV end- 

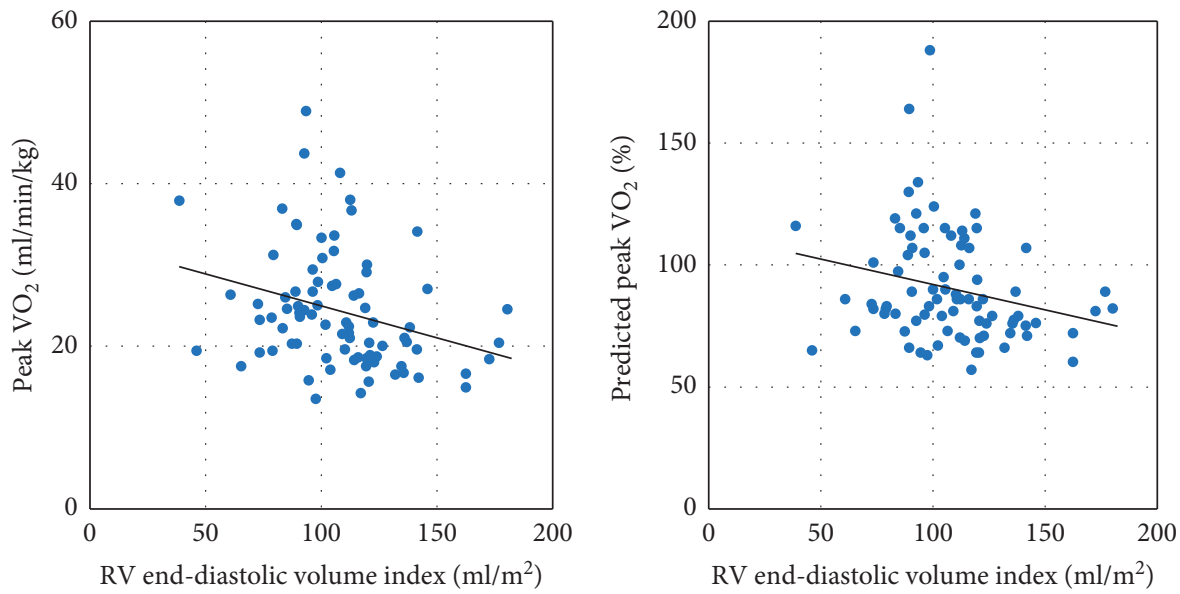

FIGURE 1: Relationships of RV volume with exercise capacity. There were significant negative relationships of RV end-diastolic volume index with peak $\mathrm{VO}_{2}$ and predicted peak $\mathrm{VO}_{2} . \mathrm{RV}=$ right ventricular; $\mathrm{VO}_{2}=$ oxygen uptake.

TABLE 4: Multivariate linear regression analysis for peak $\mathrm{VO}_{2}$.

\begin{tabular}{lccc}
\hline Variables & Beta & $95 \%$ of CI & $\begin{array}{c}p \\
\text { value }\end{array}$ \\
\hline RV end-diastolic volume index & -0.35 & $(-0.10,-0.008)$ & 0.02 \\
Mean pulmonary artery & 0.01 & $(-031,0.34)$ & 0.91 \\
pressure & 0.15 & $(-0.75,2.33)$ & 0.31 \\
Cardiac output & 0.20 & $(-1.05,4.28)$ & 0.23 \\
Qp/Qs & -0.05 & $(-0.37,0.26)$ & 0.74 \\
ASD diameter & 0.08 & $(-0.29,0.60)$ & 0.51 \\
RV FAC & -0.05 & $(-0.62,0.45)$ & 0.76 \\
TAPSE & 0.20 & $(-0.30,0.60)$ & 0.16 \\
S & &
\end{tabular}

$\mathrm{ASD}=$ atrial septal defect; $\mathrm{CI}=$ confidence interval; $\mathrm{FAC}=$ fractional area change; $\mathrm{Qp} / \mathrm{Qs}=$ pulmonary to systemic flow ratio; $\mathrm{RV}=$ right ventricular; $S=$ tricuspid annular systolic velocity; TAPSE $=$ tricuspid annular plane systolic excursion; $\mathrm{VO}_{2}=$ oxygen uptake.

diastolic volume tended to be negatively related to cardiac output. Further studies are needed in order to investigate the relationship between RV dilatation and decreased cardiac output.

In the present study, RV end-diastolic volume was evaluated by CMR imaging. CMR imaging can be used to accurately quantify RV volume, although there are certain limitations in echocardiography for assessing RV volume because of the complex anatomy and structure of the right ventricle. Even three-dimensional echocardiography is inadequate [20]. These factors may influence our result that RV dilatation evaluated by CMR imaging was closely related to exercise capacity.

The present study showed that RV ejection fraction was negatively related to peak $\mathrm{VO}_{2}$. Following Starling's law of the heart, the increased preload results in high ventricular ejection function. The parameters of RV function such as RV ejection fraction, TAPSE, S, and RV FAC tend to be elevated in patients with ASD and are decreased after device closure [21-23]. The degree of RV ejection fraction depends on RV volume overload. Therefore, the relationship between RV ejection fraction and peak $\mathrm{VO}_{2}$ may be induced by $\mathrm{RV}$ volume overload, similar to the relationship with $\mathrm{RV}$ dilatation. With regards to echocardiographic parameters, TAPSE, S, or RV FAC was not related to exercise capacity. The long axis RV function alone such as TAPSE and $S$ and the radial RV function alone such as RV FAC may be insufficient for the functional assessments.

4.1. Clinical Implications. A significant left-to-right shunt with RV dilatation or Qp/Qs $>1.5$ is indication of transcatheter ASD closure [8]. The value of Qp/Qs is widely used for the planning of therapeutic strategies. However, the clinical significance of RV dilatation, including the relationship with clinical symptoms, has not been well investigated. Further, the degree of RV dilatation that requires transcatheter ASD closure remains unclear. The present study showed that RV dilatation was related to exercise capacity in asymptomatic or mildly symptomatic patients. $\mathrm{RV}$ end-diastolic volume $\geq 120 \mathrm{ml} / \mathrm{m}^{2}$ predicted the reduction of peak $\mathrm{VO}_{2}$. Our results support that $\mathrm{RV}$ dilatation is valuable for determining the optimal timing of transcatheter ASD closure.

4.2. Study Limitations. There are some limitations in the present study. First, the number of patients was small. Large studies are required to confirm our findings. Second, exercise capacity was influenced by several factors, but noncardiac factors such as pulmonary function and skeletal muscle function were not evaluated. Third, some patients with atrial fibrillation were included in this study. The presence of atrial fibrillation might affect exercise capacity. Finally, the RV ejection fraction value was low compared with previous studies [24]. Thus, the calculation of RV ejection fraction might be underestimated in this study.

\section{Conclusions}

There was a relationship between RV dilatation and exercise capacity in adult patients with ASD. RV end-diastolic volume index $\geq 120 \mathrm{ml} / \mathrm{m}^{2}$ was related to the reduction in peak 
$\mathrm{VO}_{2}$. Our findings suggest that this criterion of RV dilatation is valuable for the indication of transcatheter ASD closure.

\section{Abbreviations and Acronyms}

ASD: Atrial septal defect

CMR: Cardiac magnetic resonance

CPET: Cardiopulmonary exercise test

FAC: Fractional area change

LV: $\quad$ Left ventricular

Qp/Qs: Pulmonary to systemic flow ratio

RV: $\quad$ Right ventricular

S: $\quad$ Tricuspid annular systolic velocity

TAPSE: Tricuspid annular plane systolic excursion

$\mathrm{VCO}_{2}$ : Carbon dioxide production

VE: $\quad$ Minute ventilation

$\mathrm{VO}_{2}$ : Oxygen uptake.

\section{Data Availability}

The data used to support the findings of this study are available from the corresponding author upon request.

\section{Conflicts of Interest}

The authors declare that they have no conflicts of interest.

\section{References}

[1] M. Oster, A. B. Bhatt, E. Zaragoza-Macias, N. Dendukuri, and A. Marelli, "Interventional therapy versus medical therapy for secundum atrial septal defect: a systematic review (part 2) for the 2018 AHA/ACC guideline for the management of adults with congenital heart disease: a report of the American college of cardiology/American heart association task force on clinical practice guidelines," Circulation, vol. 139, no. 14, pp. e814-e830, 2019.

[2] Y. Takaya, T. Akagi, Y. Kijima, K. Nakagawa, S. Sano, and H. Ito, "Long-term outcome after transcatheter closure of atrial septal defect in older patients," JACC: Cardiovascular Interventions, vol. 8, no. 4, pp. 600-606, 2015.

[3] J. I. E. Hoffman and S. Kaplan, "The incidence of congenital heart disease," Journal of the American College of Cardiology, vol. 39, no. 12, pp. 1890-1900, 2002.

[4] J. G. Murphy, B. J. Gersh, M. D. McGoon et al., "Long-term outcome after surgical repair of isolated atrial septal defect," New England Journal of Medicine, vol. 323, no. 24, pp. 1645-1650, 1990.

[5] S. C. Mitchell, S. B. Korones, and H. W. Berendes, "Congenital heart disease in 56,109 births incidence and natural history," Circulation, vol. 43, no. 3, pp. 323-332, 1971.

[6] T. Akagi, "Current concept of transcatheter closure of atrial septal defect in adults," Journal of Cardiology, vol. 65, no. 1, pp. 17-25, 2015.

[7] J. Moore, S. Hegde, H. El-Said et al., "Transcatheter device closure of atrial septal defects," JACC: Cardiovascular Interventions, vol. 6, no. 5, pp. 433-442, 2013.

[8] H. Baumgartner, P. Bonhoeffer, N. M. De Groot et al., "ESC guidelines for the management of grown-up congenital heart disease (new version 2010)," European Heart Journal, vol. 31, pp. 2915-2957, 2010.

[9] Y. Takaya, M. Taniguchi, T. Akagi et al., "Long-term effects of transcatheter closure of atrial septal defect on cardiac remodeling and exercise capacity in patients older than 40 years with a reduction in cardiopulmonary function," Journal of Interventional Cardiology, vol. 26, no. 2, pp. 195-199, 2013.

[10] M. Humenberger, R. Rosenhek, H. Gabriel et al., "Benefit of atrial septal defect closure in adults: impact of age," European Heart Journal, vol. 32, no. 5, pp. 553-560, 2011.

[11] A. A. Khan, J.-L. Tan, W. Li et al., "The impact of transcatheter atrial septal defect closure in the older population," JACC: Cardiovascular Interventions, vol. 3, no. 3, pp. 276-281, 2010.

[12] O. Salehian, E. Horlick, M. Schwerzmann et al., "Improvements in cardiac form and function after transcatheter closure of secundum atrial septal defects," Journal of the American College of Cardiology, vol. 45, no. 4, pp. 499-504, 2005.

[13] M.-C. Brochu, J.-F. Baril, A. Dore, M. Juneau, P. De Guise, and L.-A. Mercier, "Improvement in exercise capacity in asymptomatic and mildly symptomatic adults after atrial septal defect percutaneous closure," Circulation, vol. 106, no. 14, pp. 1821-1826, 2002.

[14] A. Giardini, A. Donti, R. Formigari et al., "Determinants of cardiopulmonary functional improvement after transcatheter atrial septal defect closure in asymptomatic adults," Journal of the American College of Cardiology, vol. 43, no. 10, pp. 1886-1891, 2004.

[15] T. Geva, J. D. Martins, and R. M. Wald, "Atrial septal defects," The Lancet, vol. 383, no. 9932, pp. 1921-1932, 2014.

[16] M. A. Konstam, M. S. Kiernan, D. Bernstein et al., "Evaluation and management of right-sided heart failure: a scientific statement from the American heart association," Circulation, vol. 137, no. 20, pp. e578-e622, 2018.

[17] A. E. Weyman, S. Wann, H. Feigenbaum, and J. C. Dillon, "Mechanism of abnormal septal motion in patients with right ventricular volume overload: a cross-sectional echocardiographic study," Circulation, vol. 54, no. 2, pp. 179-186, 1976.

[18] K. A. Popio, R. Gorlin, L. E. Teichholz, P. F. Cohn, D. Bechtel, and M. V. Herman, "Abnormalities of left ventricular function and geometry in adults with an atrial septal defect," The American Journal of Cardiology, vol. 36, no. 3, pp. 302-308, 1975.

[19] A. Giardini, A. Donti, S. Specchia, R. Formigari, G. Oppido, and F. M. Picchio, "Long-term impact of transcatheter atrial septal defect closure in adults on cardiac function and exercise capacity," International Journal of Cardiology, vol. 124, no. 2, pp. 179-182, 2008.

[20] E. Ostenfeld, M. Carlsson, K. Shahgaldi, A. Roijer, and J. Holm, "Manual correction of semi-automatic three-dimensional echocardiography is needed for right ventricular assessment in adults; validation with cardiac magnetic resonance," Cardiovasc Ultrasound, vol. 10, no. 1, 2012.

[21] O. Monfredi, M. Luckie, H. Mirjafari et al., "Percutaneous device closure of atrial septal defect results in very early and sustained changes of right and left heart function," International Journal of Cardiology, vol. 167, no. 4, pp. 1578-1584, 2013.

[22] V. S. Akula, R. Durgaprasad, V. Velam, L. Kasala, M. Rodda, and H. V. Erathi, "Right ventricle before and after atrial septal defect device closure," Echocardiography, vol. 33, no. 9, pp. 1381-1388, 2016.

[23] D. Kong, L. Cheng, L. Dong et al., "Three-dimensional echocardiography in the evaluation of right ventricular global and regional systolic function in patients with atrial septal defect before and after percutaneous closure," Echocardiography, vol. 33, no. 4, pp. 596-605, 2016.

[24] S. S. Stephensen, K. Steding-Ehrenborg, U. Thilén et al., "Changes in blood volume shunting in patients with atrial septal defects: assessment of heart function with cardiovascular magnetic resonance during dobutamine stress," Cardiovascular Imaging, vol. 18, no. 10, pp. 1145-1152, 2017. 